\title{
OPEN Synthesis, delivery, and molecular docking of fused quinolines as inhibitor of Hepatitis A virus $3 C$ proteinase
}

\author{
Mehrnaz Rafiei Jorshari, Manouchehr Mamaghani ${ }^{\bowtie}$ \& Parivash Jahanshahi
}

It is widely accepted that Hepatitis A virus (HAV) is responsible for liver failure and even death in older people and in people with other serious health issues; so, proposing new compounds with inhibitory activity can help to treated of these disease's. In current study, a new class of quinolines is proposed with inhibitor activity of the HAV proteinase. So, in the first step, fused quinoline derivatives has been synthesized in short reaction time $(12.0 \mathrm{~min})$ and high efficiency yields $(94 \%)$ in presence of 1-carboxymethyl-2,3-dimethylimidazolium iodide ([cmdmim]l) ionic liquid catalyst using a new method. In the following, chemical reactivity and inhibitory activity of synthesized quinolines were evaluated in density functional theory (DFT) framework and molecular docking methodologies. High

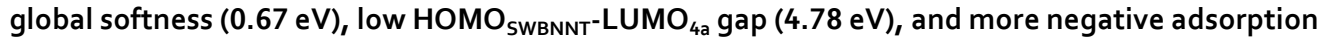
energy $\left(-87.9 \mathrm{~kJ} \mathrm{~mol}^{-1}\right)$ in these quinolines reveal that the $4 \mathrm{a}$ and $4 \mathrm{~b}$ compounds have better delivery than other quinolines using SWBNNT as suitable carrier to target cells. Molecular docking shows that the best cavity of the HAV has $-134.2 \mathrm{~kJ} \mathrm{~mol}^{-1}$ interaction energy involving bonding and non-bonding interactions. In fact, these interactions are between fused quinolines with especial geometries and sidechain flexibility amino acids residues inside the best binding site of the HAV, as hydrogen bonding, steric, and electrostatic interactions. So, these interactions imply that proposed fused quinolines have good inhibitor activity for the HAV.

Human Hepatitis A virus (HAV) is regarded as an inflammation of the liver that this infectious or epidemic hepatitis is transmitted by the fecal-oral route ${ }^{1-3}$. Low time between infection and symptoms, high rate of infection are strong reasons for motivations scientists whose always looking for logical solutions in order to help to liver disease $^{4,5}$. Albeit, it should not be forgotten that drug design and production are time consuming and complicated. In order to decrease these issues, chemistry research groups partially help with suggestion of design and synthesis new compounds with anti-virus properties. In current study, we propose derivatives of a category of organic compound called fused quinoline.

Quinolines are an important group of heterocyclic compounds that have significant biological properties ${ }^{6-10}$. In fact, these compounds are used as potential anti-cancer, anti-tumor, and anti-malarials agents ${ }^{11-13}$. There are several proposed methods to synthesis of these compounds ${ }^{14-37}$, such as Povarov reaction ${ }^{14}$, radiation to second type amines ${ }^{15}$ and so on ${ }^{14-40}$. For example, for the first time, interaction of quinolines and solid support was carried out using microwaves with solvent free technique ${ }^{6}$. In another study, compounds based on quinoline were proposed as inhibitor production of the envelope glycoprotein in Dengue Virus Serotype 2 and DNA gyrase through direct binding to the bacterial chromosome ${ }^{40}$. Also, these compounds were designed and synthesized for DNA-gyrase and topoisomerase-II inhibition ${ }^{41}$. Another series of quinolines has been prepared as MEK (MAP kinase kinase) inhibitors ${ }^{42}$. In addition, synthesized quinolines via the Mannich reaction were prepared against Gram-positive (G+), Gram-negative (G-) bacteria ${ }^{39}$.

Although above mentioned studies have proposed methods with the aim using into pharmaceutical industries, they have low relative yield and high reaction time. So, in current study, we propose a novel method to synthesis of fused quinolines with excellent yield and short reaction time using 1-carboxymethyl-2,3-dimethylimidazolium iodide $([\mathrm{cmdmim}] \mathrm{I})$ ionic liquid catalyst ${ }^{43}$. In fact, the $[\mathrm{cmdmim}] \mathrm{I}$ as one of recyclable catalysts mainly results in straightforward work-up procedure, and reusability of the catalyst in about 5 consecutive runs without any appreciable decrease in activity ${ }^{43}$. In fact, ionic liquids have important role into synthesis of these compounds on pharmaceutical industries. On the other hands, we are going to study quantum mechanics calculations due 
to introduce suitable quinolines with high chemical reactivity. In addition, their inhibitory activity in interaction with the HAV will study using molecular docking computations.

\section{Experimental section}

General. Chemicals were purchased from the Merck chemical companies. Extend of reactions were evaluated by thin layer chromatography (TLC) covered using silica-gel 60, F256 contracted by Merck chemical companies. In the TLC chromatography was used from $n$-Hexane and Ethyl Acetate solvents. Melting point was recorded using electro thermal devices. FT-IR, ${ }^{1} \mathrm{H}-\mathrm{NMR}$ and ${ }^{13} \mathrm{C}-\mathrm{NMR}$ spectra were recorded using VERTIX 70 Brucker, a Brucker (400 MHz) Advance DRX in DMSO-d6 solvent. Chemical shift (in ppm) were investigated in related to tetra methyl silane (TMS) as internal standard.

Preparation of the [cmdmim] I ionic liquid. The [ $\mathrm{cmdmim}] \mathrm{I}$ ionic liquid is high impact catalyst with solid state and orange color; whose previously synthesized by our research group ${ }^{43}$.

Synthesis of the 7-(3-Nitro-Phenyle)-H8-Benzo [h] Indo [1.2-b] quinoline-8-on (4a). In balloon flask $(100 \mathrm{~mL})$ equipped with an electrical condenser, a mixture consisting of 1,3 -indandeion $(0.146 \mathrm{~g}$, $1 \mathrm{mmol})$, 3-Nitro Benzaldehide $(0.1510 \mathrm{~g}, 1 \mathrm{mmol})$, and 1-Naphtyle Amine (0.143 g, $1 \mathrm{mmol})$, in presence of the [cmdmim] I ionic liquid catalyst $(10 \%$ molar), water solvent $(10.0 \mathrm{~mL})$ was heated for $15 \mathrm{~min}$ at reflux conditions. The progress of the reaction was followed by the TLC (eluting with a mixture of Petroleum Ether, Ethyl Acetate (3:10), accompanied one drop of Methanol). After cooling and solvent evaporation, the mixture of reaction was dissolved in Ethanol, Ethyl Acetate, and Chloroform (30:30:10 mL) and then, it was purified and dried. The yellow powder of the synthesized compound $(4 \mathrm{a} ; 0.361 \mathrm{~g})$ was produced in $90.0 \%$ yield and $326-328^{\circ} \mathrm{C}$. Other quinoline derivatives are produced using proposed method, see Table S1 and S2 (S means supplementary file).

The $4 \mathrm{a}$ synthesis has been carried out in various conditions such as six different solvents, $10 \%$ molar of catalyst, and reflux condition, see Table S3. Influence of different catalyst and their value have been evaluated after investigation of reliable solvent, see Tables S2 to S5. According to Tables S4 and S5, the most favorable condition for the $4 \mathrm{a}$ synthesis was using $10 \%$ molar catalyst in water solvent and reflux condition.

To confirmation of produced structures, $4 \mathrm{a}$, the IR, ${ }^{1} \mathrm{H}-\mathrm{NMR}$ and ${ }^{13} \mathrm{C}-\mathrm{NMR}$ spectroscopies were used. IR (KBr): 3062 (C-H stretch, aromatic), 1710 (C=O stretch), 1639 (C=N stretch), 1608, 1571, 1469 (C-C stretch, aromatic), 1519, 1346 (NO2 stretch), 844, 815, 763, 730 (C-H out of plane bending, aromatic) $\mathrm{cm}^{-1} .{ }^{1} \mathrm{H}-\mathrm{NMR}$ (400 MHz, DMSO) $\delta$ (ppm): He or Hh $9.46(\mathrm{dd}, \mathrm{J}=2$ and $8.2 \mathrm{~Hz}, 1 \mathrm{H})$, He or Hh and Hk 8.47-8.50 (m, 2H), Hl $8.27(\mathrm{~d}, \mathrm{~J}=7.2 \mathrm{~Hz}, 1 \mathrm{H})$, Ha or Hd $8.04(\mathrm{~d}, \mathrm{~J}=7.6 \mathrm{~Hz}, 1 \mathrm{H}), \mathrm{Hj} 7.98(\mathrm{~d}, \mathrm{~J}=8.8 \mathrm{~Hz}, 1 \mathrm{H}), \mathrm{Hc} 7.93(\mathrm{t}, \mathrm{J}=6.2 \mathrm{~Hz}, 1 \mathrm{H})$, $\mathrm{Hm}, \mathrm{Hb}$ and $\mathrm{Hf}$ or $\mathrm{Hg} 7.86-7.93(\mathrm{~m}, 3 \mathrm{H}), \mathrm{Hn} 7.73(\mathrm{~d}, \mathrm{~J}=7.2 \mathrm{~Hz}, 1 \mathrm{H}), \mathrm{Hg}$ or Hf $7.66(\mathrm{t}, \mathrm{J}=7.2 \mathrm{~Hz}, 1 \mathrm{H}), \mathrm{Hi} 7.52$ $(\mathrm{d}, \mathrm{J}=8.8 \mathrm{~Hz}, 1 \mathrm{H}) .{ }^{13} \mathrm{C}-\mathrm{NMR}(100 \mathrm{MHz}, \mathrm{DMSO}-\mathrm{d} 6) \delta(\mathrm{ppm}): \mathrm{C}=\mathrm{O}$ ketone 192, 24 aromatic Carbone: 162.5, $160.5,154.2,150.7,148.4,146.5,144.0,141.9,139.9,139.7,137.6,135.9,135.4,133.1,131.3,129.1,128.7,128.3$, $125.6,125.0,124.6,124.5,123.6,122.9$, and 121.9.

Theoretical section. Low lying structure have been investigated in the framework of hybrid-DFT (H-DFT) by using Gaussian09 program package ${ }^{44}$. The $\omega \mathrm{B} 97-\mathrm{XD} / 6-31 \mathrm{~g}(\mathrm{~d})$ level of theory was selected using DFT calibration method ${ }^{45,46}$; which combines long range correlation functionals, with all electron basis set, 6-31g(d) ${ }^{47}$. Geometry optimization of structures carried out without any symmetry constrains (C1 symmetry). Vibrational frequency test guarantees that the optimized geometries are in real minima.

Tendency and role of the SWBNNT, the $4 \mathrm{a}$, and derivatives in their interactions have been investigated using global chemical reactivity descriptors such as chemical potential $(\mu=-(\mathrm{IE}+\mathrm{EA}) / 2)$, hardness $(\eta=(\mathrm{IE}-\mathrm{EA}) / 2)$, softness $(S=1 / \eta)$, and electrophilicity $(\omega=\mu 2 / 2 \eta)^{48}$. In fact, the $\mu$ is the escaping tendency of electrons, the $\eta$ is a resistance to charge transfer, the $\omega$ is floating of electron between nucleophile and electrophile. The IE and EA are adiabatic ionization energy and electron affinity, respectively; they calculated using tree approach point methods:

$$
\begin{gathered}
\mathrm{IE}_{a d}=\mathrm{E}_{\text {total }}\left(\text { compound }{ }^{+}\right)-\mathrm{E}_{\text {total }}(\text { compound }) \\
E A=\mathrm{E}_{\text {total }}(\text { compound })-\mathrm{E}_{\text {total }}\left(\text { compound }{ }^{-}\right)
\end{gathered}
$$

where $\mathrm{E}_{\text {total }}$ (compound), $\mathrm{E}_{\text {total }}$ (compound ${ }^{+}$), and $\mathrm{E}_{\text {total }}$ (compound ${ }^{-}$) are total energy of neutral, cationic, and anionic compounds (SWBNNT and fused quinoline derivatives), respectively. Thermodynamic stability of complexes was calculated using adsorption energy equation:

$$
\mathrm{E}_{a d s}=\mathrm{E}_{S W B N N T / 4 \mathrm{a}}-\left(\mathrm{E}_{S W B N N T}+\mathrm{E}_{\text {fused quinoline derivatives }}\right)
$$

where $\mathrm{E}_{S W B N N T / 4 \mathrm{a}}, \mathrm{E}_{S W B N N T}$, and $\mathrm{E}_{\text {fused quinoline derivatives }}$ are total energy of complexes, SWBNNT, and fused quinoline derivatives molecule, respectively. In order to achievement to realistic value of the $\mathrm{E}_{\mathrm{ads}}$, zeropoint vibrational energy (ZPVE) and basis set supper position error (BSSE) was considered. Therefore, the counterpoise correlation was used to correct BSSE error. Geometric information is completed by results of natural bond orbital (NBO) analysis. Type of bonds, depletion of occupancies, percent of Lewis and non-Lewis and stabilization energy $\left(\mathrm{E}_{\mathrm{ij}}^{2}\right)$ are obtained by NBO analysis:

$$
E_{i j}^{2}=\frac{|\langle i|\hat{H}| j\rangle|^{2}}{E_{j}-E_{i}}
$$




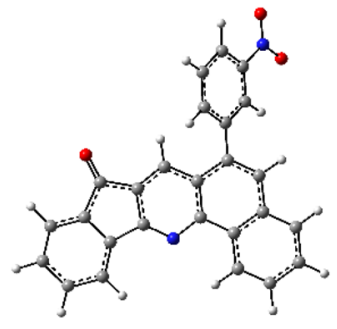

$4 a$

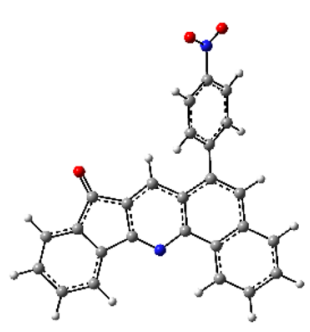

$4 b$

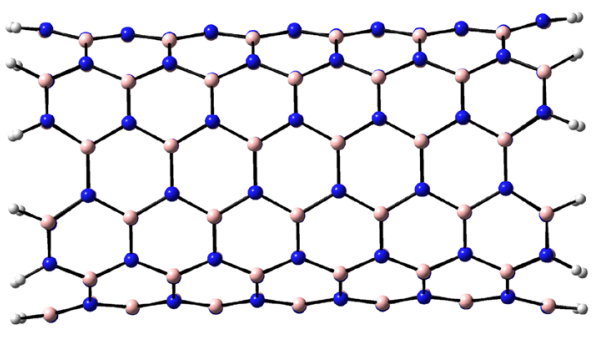

SWBNNT

Figure 1. Ground state structure of the $4 \mathrm{a}, 4 \mathrm{~b}$, and single walled boron nitride nanotube (SWBNNT) in $\omega \mathrm{B} 97-$ $\mathrm{XD} / 6-31 \mathrm{~g}^{*}$ level of theory.<smiles>O=C1CC(=O)c2ccccc21</smiles><smiles>O=Cc1cccc([N+](=O)[O-])c1</smiles><smiles>Nc1cccc2ccccc12</smiles><smiles>O=C1c2ccccc2-c2nc3c(ccc4ccccc43)c(-c3cccc([N+](=O)[O-])c3)c21</smiles>

Scheme 1. The synthetic pathway toward synthesis of 4 a compound in reflux condition.

where $\hat{H}$ is interaction Hamiltonian, $E_{j}$ and $E_{i}$ are orbital energies, and $\langle i|\hat{H}| j\rangle$ is matrix element.

Molecular docking. Secondary structures of Hepatitis A virus (PDB ID: 1HAV) were retrieved from the Research Collaboratory for Structural Bioinformatics (RCSB) Protein Data Bank (http://www.rcsb.org/), see Figure S4. In geometry minimization processing, the best of their potential ligand binding site (cavity) has X: 11.96, Y: 5.87, Z: 10.08 Cartesian coordinate, radius $15 \AA$, volume $1438.2 \AA^{3}$, and surface $2420.5 \AA^{2}$, respectively. Maximum global minimization step for molecular docking was set at 1500 steps. The side chain flexibility of the amino acid residues of these proteins inside the cavity with tolerance of 1.00 and strength of 0.90 were considered, see Fig. 1.

Then, molecular docking was simulated using Molegro Virtual Docker (MVD) 6.01 ${ }^{49}$. For this purpose, MolDock algorithm as docking method based on guided differential evolution (combination differential evolution optimization technique with cavity prediction algorithm) and force field based scoring function [extension of Piecewise Lenear Potential (PLP) $]^{50}$ identify the potential binding site of proteins and binding orientation of ligands $s^{50}$. Re-ranking of top ranked conformations mainly results in improvement of docking accuracy ${ }^{51}$. The MolDock scoring function iteration was set 1500 with a simplex evolution size of 50 and a minimum of 10 runs. In addition, the simplex evolution was set for 300 steps with a neighbor distance factor of 1.00. The MolDock grid score was set with a grid resolution of $0.30 \AA$.

\section{Results and discussion}

In starting point, optimization processing of reaction condition for synthesis of Indo-quinoline derivatives was carried out in different solvent and catalysts; see Table S1. The most efficiency yields (90.0\%) was obtained in $10 \%$ molar the $[\mathrm{cmdmim}] \mathrm{I}$ ionic liquid catalyst and reflux condition in the water as green solvent. This efficiency mainly results from selection of the 1,3-indandione, aryl aldehydes and 1-naphthylamine with the same ratio in one pot reaction, see Scheme 1.

In the proposed reaction mechanism, Scheme S1, aryl aldehydes are the key component in this reaction due to especial geometry. More importantly, role of ionic liquid in proposed mechanism (Scheme S1) is activation of aldehyde and ketone carbonyl and facilitating of reaction cyclo addition step, respectively, see Scheme S2.

The main aim of current study is to provide a conceptual theoretical framework based on $\omega \mathrm{B} 97-\mathrm{XD} / 6-31 \mathrm{~g}^{*}$ method. Geometry of quinoline derivatives in the real minima are given in Fig. 1 and Figure S1. In fact, synthesized fused quinolines are susceptible non-covalent interactions.

High electron density in the molecular electrostatic potential (MEP) maps ${ }^{52}$, confirms non bond interaction, as shown in Fig. 2 and Figure S1. This property can give into inhibitory activity on Hepatitis A virus. The MEP maps $^{52}$, investigate and predict active sites and strength of interactions in the $4 \mathrm{a}$, derivatives and SWBNNT. According to this figure, despite areas without electron density (green color) in the 4a and SWBNNT, Oxygen 


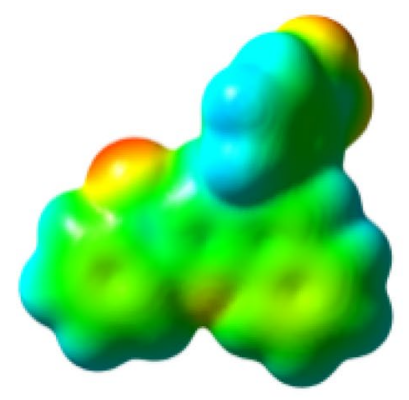

4a

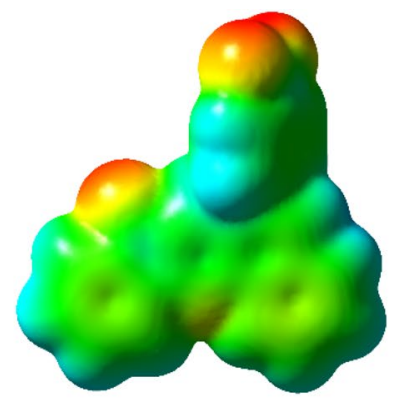

4b

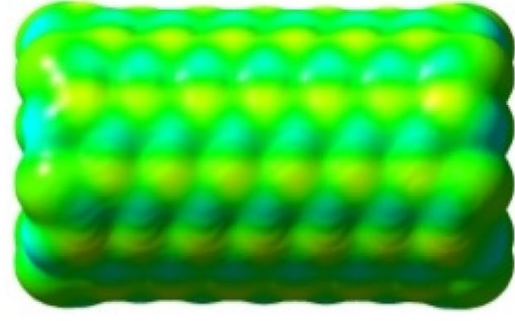

SWBNNT

Figure 2. Molecular electrostatic potential (MEP) maps of the $4 \mathrm{a}, 4 \mathrm{~b}$, and single walled boron nitride nanotube (SWBNNT) in $\omega \mathrm{B} 97-\mathrm{XD} / 6-31 \mathrm{~g}^{\star}$ level of theory.

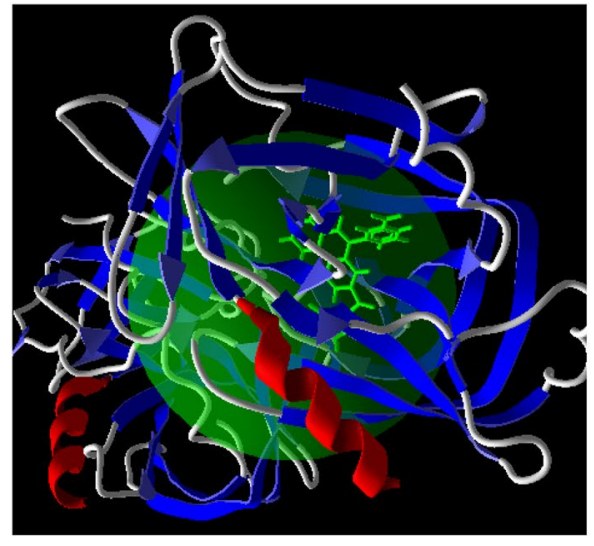

(4a)

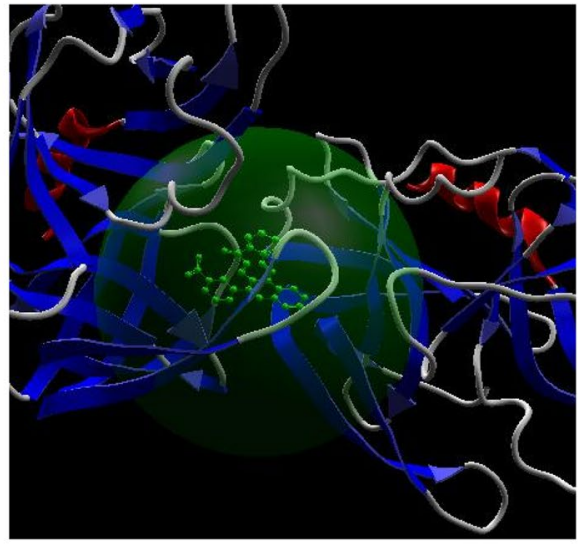

(4b)

Figure 3. Molecular simulation of the $4 \mathrm{a}, 4 \mathrm{~b}$, and Hepatitis virus.

and Nitrogen centers in the 4a molecule show negative electrostatic potential. In fact, these parts with electron delocalization can introduce as involve sites in their interactions.

The more charge transfer is carried out from SWBNNT to 4 a molecule due to lower the $\mathrm{HOMO}_{\mathrm{SWBNNT}}-\mathrm{LUMO}_{4 \mathrm{a}}$ gap than others, see Figure S2. This issue confirms by $125 \mathrm{kcal} \mathrm{mol}^{-1}$ in total second order stabilization energy.

With investigating of their role, they were interacted in suitable orientations, see Figure S3. Energy of stable configurations was considered to calculate of adsorption energy $\left(\mathrm{E}_{a d s}\right)$. Based on the more negative value of the $\mathrm{E}_{a d s}, 4 \mathrm{a}$ and $4 \mathrm{~b}$ complex has adsorption strength and stable configuration than others, as shown in Table S8.

Density of state (DOS) analysis has been carried out due to better understanding of these interactions. Total DOS of the 4a molecule, SWBNNT, and outside complexes are given in Figure S1. The reduction of energy gaps in complexes can be attributed to better interactions. These interactions may influence on electron excitation and excited states spectrum.

After delivery of drug molecule to target cells involving Hepatitis A virus, their interactions are important. The best geometry of docking has more negative value in Gibbs free energy at $25 \mathrm{~ns}$, see Fig. 3 . The best favorable sites of fused quinoline rings as drug molecule interact with Hepatitis A virus from the hydrogen bonding, electrostatic, and steric interactions.

Molecular docking. The best binding cavity for each molecular docking simulation using the MVD program package are shown in Fig. 4. Docking scoring results in best selected cavity are presented in Table 1. More negative re-rank score showing better docking of ligand into active site of Hepatitis A virus. According to this table, re-rank score in Hepatitis A virus is negative. Molecular interaction energy between ligand and Hepatitis A virus is $-134.6 \mathrm{~kJ} \mathrm{~mol}^{-1}$. Besides, deep bonded and non-bonded interaction ligand inside the binding pocket of Hepatitis A virus indicating strong molecular interaction involving both interactions. Although these interactions are with Val $(41,85,86,204)$, Leu $(40,78,119,176)$, Gly $(173,174,189)$, Met $(29,30)$, His (191), Ile (190), Ala (175), Thr(121), Cys (172), Pro (42) residues of Hepatitis A virus. These interactions at the active site of ligand are presented in Fig. 5. Indeed, introduced active sites of proteins have high-affinity for binding into ligand molecule at binding region. This result is in good agreement with chemical reactivity descriptors. Green, 


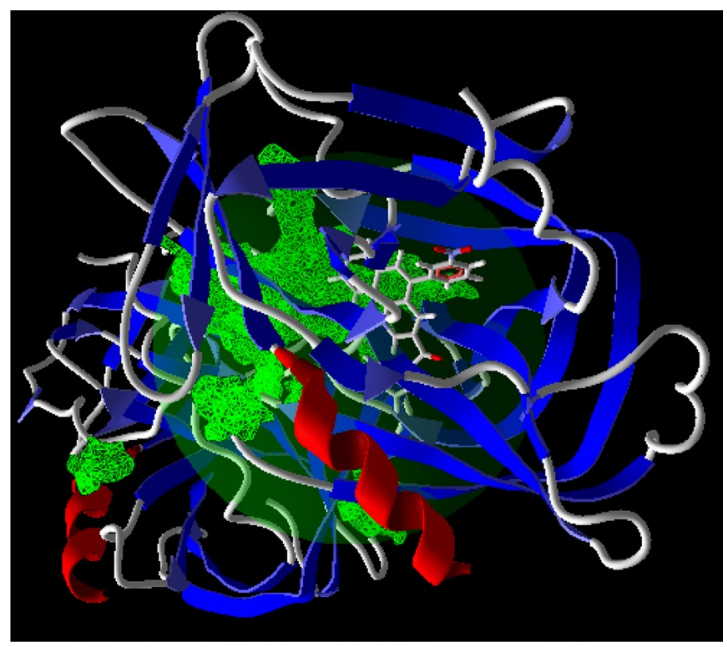

Figure 4. The potential ligand binding cavities of Hepatitis virus.

\begin{tabular}{|l|l|l|l|l|}
\hline Protein-ligand & RS & $\mathbf{E}_{\text {tot }}$ & IE & $\mathbf{E}_{\mathrm{HB}}$ \\
\hline HAV-4a & -43.31 & -134.60 & -16.76 & -5.23 \\
\hline HAV-4b & -39.02 & -127.04 & -13.43 & -3.23 \\
\hline
\end{tabular}

Table 1. Molecular docking score of Hepatitis A virus with ligand (4a and $4 \mathrm{~b}$ ) in the favorable cavity. RS Re-rank score is linear combination of internal (Steric, Van der Waals, Hydrogen bonding, and Electrostatic) and external (Torsion strain, Torsion strain $\mathrm{sp}^{2}-\mathrm{sp}^{2}$, Hydrogen bonding, Van der Waals, and Electrostatic) energies. $E_{\text {tot }}$ total interaction energy between protein and pose, $I E$ internal energy of pose, $E_{H B}$ hydrogen bonding energy.

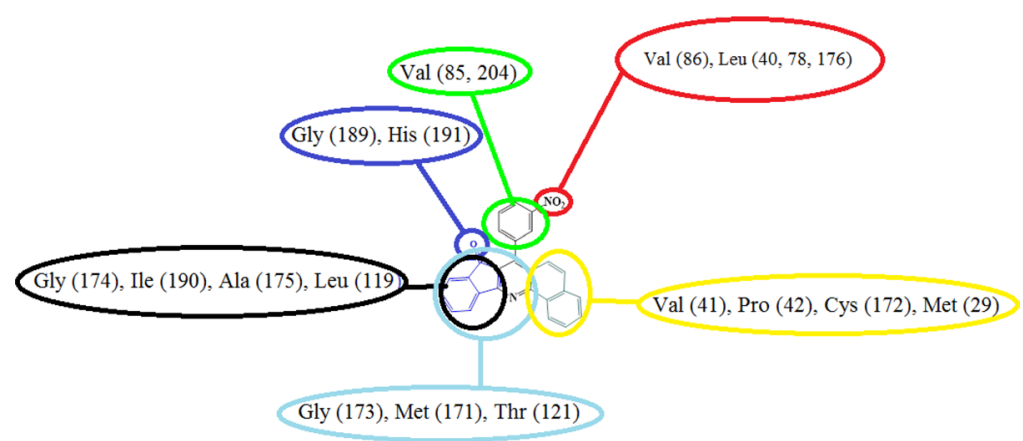

Figure 5. Molecular interaction between fused quinoline (4a, $4 \mathrm{~b})$ and active site of Hepatitis virus.

turquoise, yellow, red and blue colors in the energy map of Hepatitis virus might contribute in favorable steric interaction, hydrogen acceptor, hydrogen donor, electrostatic potential with the ligand ${ }^{51}$. While steric, hydrogen donor and electrostatic potential interaction are the most probably interaction in Hepatitis A virus, steric interaction is the most probably interaction, see Fig. 6. So, these results imply favorable ligand-protein interaction energy at the binding cavity of Hepatitis virus. In addition, it can be proposed this ligand with relatively good inhibitor.

\section{Conclusion}

In summary, one pot three component reaction in presence mentioned ionic liquid catalyst and condition is good strategies to synthesis of fused quinolines with excellent efficiency. As well as that, using of this catalyst satisfies green chemistry aims. SWBNNT is introduced as a good carrier to transform synthesized compounds without side effects. With entrance of drug molecule into target cell involving Hepatitis virus, fused quinolones interact from oxygen and nitrogen sites. So, introduced fused quinolines are susceptible these interactions due to existence five aromatic rings. 


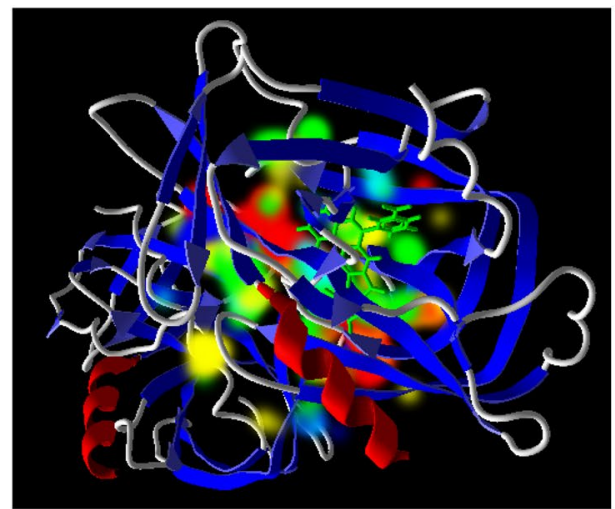

4a

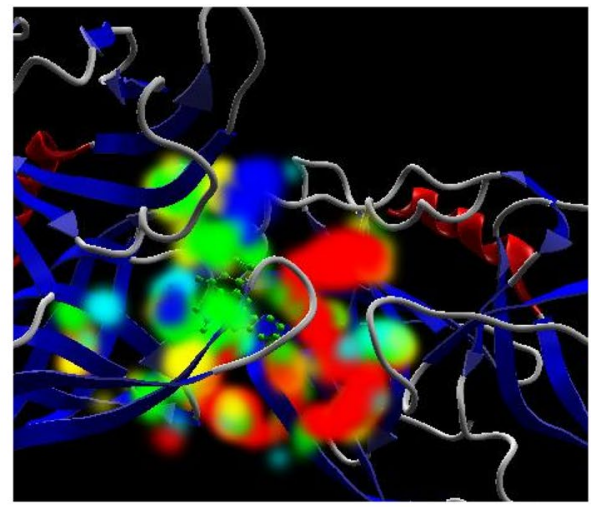

4b

Figure 6. Energy map of fused quinoline $(4 a, 4 b)$ at the binding cavity of Hepatitis virus.

Received: 17 July 2021; Accepted: 8 September 2021

Published online: 23 September 2021

\section{References}

1. Baron, S. Medical Microbiology 4th edn. (University of Texas Medical Branch, 1996).

2. Louten, J. Virus Structure and Classification. in Essential Human Virology 19-29 (Elsevier, 2016). https://doi.org/10.1016/B9780-12-800947-5.00002-8.

3. Ryu, W.-S. New emerging viruses. in Molecular Virology of Human Pathogenic Viruses 289-302 (Elsevier, 2017). https://doi.org/ 10.1016/B978-0-12-800838-6.00021-7.

4. Vos, T. et al. Global, regional, and national incidence, prevalence, and years lived with disability for 310 diseases and injuries, 1990-2015: A systematic analysis for the Global Burden of Disease Study 2015. Lancet 388, 1545-1602 (2016).

5. Global hepatitis report, 2017 (2017).

6. Kidwai, M., Bhushan, K. R., Sapra, P., Saxena, R. K. \& Gupta, R. Alumina-supported synthesis of antibacterial quinolines using microwaves. Bioorg. Med. Chem. 8, 69-72 (2000).

7. Madrid, P. B. et al. Synthesis of ring-substituted 4-aminoquinolines and evaluation of their antimalarial activities. Bioorg. Med. Chem. Lett. 15, 1015-1018 (2005).

8. Yamato, M. et al. Synthesis and antitumor activity of fused tetracyclic quinoline derivatives. 1. J. Med. Chem. 32, 1295-1300 (1989).

9. Loddo, R. et al. Synthesis and antiviral activity of new phenylimidazopyridines and N-benzylidenequinolinamines derived by molecular simplification of phenylimidazo[4,5-g]quinolines. J. Med. Chem. 84, 8-16 (2014).

10. Matada, B. S., Pattanashettar, R. \& Yernale, N. G. A comprehensive review on the biological interest of quinoline and its derivatives. Bioorg. Med. Chem. 32, 115973 (2021).

11. Abbas, S. H., Abd El-Hafeez, A. A., Shoman, M. E., Montano, M. M. \& Hassan, H. A. New quinoline/chalcone hybrids as anticancer agents: Design, synthesis, and evaluations of cytotoxicity and PI3K inhibitory activity. Bioorg. Chem. 82, 360-377 (2019).

12. Li, W. et al. Discovery of novel quinoline-chalcone derivatives as potent antitumor agents with microtubule polymerization inhibitory activity. J. Med. Chem. 62, 993-1013 (2019).

13. Kaur, K., Jain, M., Reddy, R. P. \& Jain, R. Quinolines and structurally related heterocycles as antimalarials. Eur. J. Med. Chem. 45, 3245-3264 (2010).

14. Sridhaan, V., Avendano, C. \& Convenient, J. C. M. two-step synthesis of 2-styrylquinolines: An application of the CAN-catalyzed vinylogous type-II Povarov reaction. Tetrahedron 65, 2087-2096 (2009).

15. Wilson, N. S., Sarko, C. R. \& Roth, G. P. Microwave-assisted synthesis of 2-aminoquinolines. Tetrahedron Lett. 43, 581-583 (2002).

16. Vasamsetty, S. et al. Free one-pot synthesis of chromeno quinolines and their antibacterial activity. Chem. Green Sustain. 7, 141-152 (2017).

17. Kouznetsoy, V. V., Bohorquez, A. R. R. \& Saavedra, L. A. Convenient procedure for the synthesis of new a-pyridinyl-substituted $7 \mathrm{H}$-indeno $[2,1-\mathrm{c}]$ quinoline derivatives based on a three-component imino Diels-Alder reaction. Synthesis (Stuttg) 24, 4219-4225 (2009).

18. Khaligh, N. G. \& Mihankhah, T. Poly(4-vinylpyridinium) hydrogen sulfate catalyzed synthesis of 12-aryl-12-hydro-5H-benzo[g] indeno[2,1-b]quinoline-6,11,13-trione derivatives. Res. Chem. Intermed. 41, 4569-4579 (2015).

19. Sandaroos, R., Vadi, M. \& Damavandi, S. Efficient example of cross-linked polymeric catalysed synthesis of $7 \mathrm{H}-\mathrm{benzo}$ [h] indeno[1,2-b]quinolin-8-one and 8H-naphtho[2,3-h]indeno[1,2-b]quinolin-9-one. J. Chem. Sci. 125, 1497-1501 (2013).

20. Azizian, J., Delbari, A. S. \& Yadollahzadeh, K. One-pot, three-component synthesis of pyrimido[4,5-b]quinoline-tetraone derivatives in water. Synth. Commun. 44, 3277-3286 (2014).

21. Lanza, F. et al. Development of a semiautomated procedure for the synthesis and evaluation of molecularly imprinted polymers applied to the search for functional monomers for phenytoin and nifedipine. Anal. Chim. Acta 435, 91-106 (2001).

22. Sunkel, C. E., Fau de Casa-Juana, M., Cillero, F. J., Priego, J. G. \& Ortega, M. P. Synthesis, platelet aggregation inhibitory activity, and in vivo antithrombotic activity of new 1,4-dihydropyridines. J. Med. Chem. 31, 1886-1890 (1988).

23. Budriesi, R. et al. 1,4-Dihydropyridine derivatives as calcium channel modulators: The role of 3-methoxy-flavone moiety. Bioorg. Med. Chem. 13, 3423-3430 (2005).

24. Zhou, X. et al. New 4-aryl-1,4-dihydropyridines and 4-arylpyridines as p-glycoprotein inhibitors. Drug Metab. Dispos. 33, 321-328 (2005).

25. Ozer, E. K. et al. Synthesis of fused 1,4-dihydropyridines as potential calcium channel blockers. Turk. J. Biochem. 43, 578-586 (2018).

26. Yadav, J. S., Reddy, B. V. S., Rao, R. S., Naveenkumar, V. \& Nagaiah, K. Microwave-assisted one-pot synthesis of 2,4-disubstituted quinolines under solvent-free conditions. Synthesis (Stuttg.) 10, 1610-1614. https://doi.org/10.1055/s-2003-40531 (2003).

27. Kundu, A. \& Pramanik, A. Novel synthesis of a series of spiro 1,3-indanedione-fused dihydropyridines through the condensation of a tetrone with N-aryl/alkylenamines in presence of solid support silica sulfuric acid. Mol. Divers. 19, 459-471 (2015). 
28. Nikpassand, M., Mamaghani, M. \& Tabatabaeian, K. An efficient one-pot three-component synthesis of fused 1,4-dihydropyridines using HY-zeolite. Molecules 14, 1468-1474 (2009).

29. Ko, S., Sastry, M. N. V., Lin, C. \& Yao, C. F. Molecular iodine-catalyzed one-pot synthesis of 4-substituted-1,4-dihydropyridine derivatives via Hantzsch reaction. Tetrahedron Lett. 46, 5771-5774 (2005).

30. Moghaddam, F. M., Saeidian, H., Mirjafary, Z. \& Sadeghi, A. Rapid and efficient one-pot synthesis of 1,4-dihydropyridine and polyhydroquinoline derivatives through the Hantzsch four component condensation by zinc oxide. J. Iran. Chem. Soc. 6, 317-324 (2009).

31. Shestopalov, A. M. et al. Synthesis of 3-cyano-2-fluoropyridines. J. Fluor. Chem. 130, 236-240 (2009).

32. Wang, X. M., Ye, H. L. \& Qaun, Z. J. One-pot synthesis of benzoquinoline and coumarin derivatives using Meldrum's acid in three-component reactions. Res. Chem. Intermed. 39, 2357-2367 (2012).

33. Albagli, D. et al. Measurement and analysis of neutron and gamma-ray emission rates, other fusion products, and power in electrochemical cells having Pd cathodes. J. Fusion Energy 9, 133-148 (1990).

34. Chen, D.-S., Li, Y.-L., Liu, Y. \& Wang, X.-S. Synthesis of bis-benzoquinoline derivatives catalyzed by iodine via ring-opening of furan. Tetrahedron 69, 7045-7050 (2013).

35. Maiti, G., Karmakar, R. \& Kayal, U. One pot imino Diels-Alder reaction for the synthesis of 3-aryl-3,4-dihydrobenzo[f]quinoline derivatives catalyzed by antimony trichloride. Tetrahedron Lett. 54, 2920-2923 (2013).

36. Wang, X. S., Zhou, J., Yang, K. \& Yao, C. S. Yb(OTf)3: An efficient catalyst for the synthesis of 3-arylbenzo [f] quinoline-1,2-dicarboxylate derivatives via imino-Diels-Alder reaction. Tetrahedron Lett. 51, 5721-5723 (2010).

37. Khaligh, N. G. Three-component, one-pot synthesis of benzo[f]indenoquinoline derivatives catalyzed by poly(4-vinylpyridinium) hydrogen sulfate. Chin. J. Catal. 35, 474-480 (2014).

38. Fu, H. G. et al. Synthesis and biological evaluation of quinoline derivatives as a novel class of broad-spectrum antibacterial agents. Molecules 24, 1-11 (2019).

39. Richter, S., Parolin, C., Palumbo, M. \& Palù, G. Antiviral properties of quinolone-based drugs. Curr. Drug Targets Infect. Disord. 4, 111-116 (2004)

40. de la Guardia, C. et al. Antiviral activity of novel quinoline derivatives against dengue virus serotype 2. Molecules 23, 1-11 (2018).

41. Sui, Z. et al. Synthesis and inhibitory activity of novel tri- and tetracyclic quinolines against topoisomerases. Bioorg. Med. Chem. 6, 735-742 (1998).

42. Zhang, N. et al. Synthesis and structure-activity relationships of 3-cyano-4-(phenoxyanilino)quinolines as MEK (MAPKK) inhibitors. Bioorg. Med. Chem. Lett. 10, 2825-2828 (2000).

43. Jahanshahi, P. \& Mamaghani, M. Chemodivergent, multicomponent-tandem facile synthesis of novel $1 \mathrm{H}$-pyrazolo[1,2-b]phthalazine-5,10-dione using acetic acid functionalized imidazolium salt [cmdmim] I as a recyclable catalyst. New J. Chem. 43, 8266-8278 (2019).

44. Frisch, M. et al. Gaussian 09, Revision A.1 (2009).

45. Pakiari, A. H. \& Eshghi, F. Geometric and electronic structures of vanadium sub-nano clusters, $\mathrm{Vn}(\mathrm{n}=2-5)$, and their adsorption complexes with CO and O2 ligands: A DFT-NBO study. Phys. Chem. Res. 5, 601-615 (2017).

46. Chai, J.-D. \& Head-Gordon, M. Long-range corrected hybrid density functionals with damped atom-atom dispersion corrections. Phys. Chem. Chem. Phys. 10, 6615-6620 (2008).

47. McLean, A. D. \& Chandler, G. S. Contracted Gaussian basis sets for molecular calculations. I. Second row atoms, Z $=11-18$. J. Chem. Phys. 72, 5639-5648 (1980).

48. Parr, R. G. \& Wang, Y. Density-Functional Theory of Atoms and Molecules (Oxford University Press, 1989).

49. Molegro, A. P. S. MVD 5.0 Molegro virtual docker. DK-8000 Aarhus C, Denmark (2011).

50. Thomsen, R. \& Christensen, M. H. MolDock: A new technique for high-accuracy molecular docking. J. Med. Chem. 49, 3315-3321 (2006).

51. De Azevedo, J. \& Walter, F. MolDock applied to structure-based virtual screening. Curr. Drug Targets 11, 327-334 (2010).

52. Tasi, G., Palinko, I., Nyerges, L., Fejes, P. \& Foerster, H. Calculation of electrostatic potential maps and atomic charges for large molecules. J. Chem. Inf. Comput. Sci. 33, 296-299 (1993).

\section{Acknowledgements}

The authors are grateful to Dr. Fazlolah Eshghi due to his high suggestion, doing theoretical and molecular docking studies in this work.

\section{Author contributions}

M.M. conceived of the presented idea. M.R.J. carried out computational jobs and experiments. M.R.J. and P.J. wrote the manuscript and discussed the results and contributed to the final manuscript.

\section{Competing interests}

The authors declare no competing interests.

\section{Additional information}

Supplementary Information The online version contains supplementary material available at https://doi.org/ 10.1038/s41598-021-98529-0.

Correspondence and requests for materials should be addressed to M.M.

Reprints and permissions information is available at www.nature.com/reprints.

Publisher's note Springer Nature remains neutral with regard to jurisdictional claims in published maps and institutional affiliations. 
(c) (i) Open Access This article is licensed under a Creative Commons Attribution 4.0 International cc) License, which permits use, sharing, adaptation, distribution and reproduction in any medium or format, as long as you give appropriate credit to the original author(s) and the source, provide a link to the Creative Commons licence, and indicate if changes were made. The images or other third party material in this article are included in the article's Creative Commons licence, unless indicated otherwise in a credit line to the material. If material is not included in the article's Creative Commons licence and your intended use is not permitted by statutory regulation or exceeds the permitted use, you will need to obtain permission directly from the copyright holder. To view a copy of this licence, visit http://creativecommons.org/licenses/by/4.0/.

(C) The Author(s) 2021 